Article

\title{
Evaluation of P-Glycoprotein Inhibitory Potential Using a Rhodamine 123 Accumulation Assay
}

\author{
Elodie Jouan ${ }^{1}$, Marc Le Vée ${ }^{1}$, Abdullah Mayati ${ }^{1}$, Claire Denizot ${ }^{2}$, Yannick Parmentier ${ }^{2}$ and \\ Olivier Fardel 1,3,* \\ 1 Institut de Recherches en Santé, Environnement et Travail (IRSET), UMR INSERM U1085, Faculté de \\ Pharmacie, 2 Avenue du Pr Léon Bernard, 35043 Rennes, France; elodie.jouan@gmail.com (E.J.); \\ marc.levee@free.fr (M.L.V.); abdullah.mayati@univ-rennes1.fr (A.M.) \\ 2 Centre de Pharmacocinétique, Technologie Servier, 25-27 Rue Eugène Vignat, 45000 Orléans, France; \\ claire.denizot@servier.com (C.D.); yannick.parmentier@servier.com (Y.P.) \\ 3 Pôle Biologie, Centre Hospitalier Universitaire, 2 rue Henri le Guilloux, 35033 Rennes, France \\ * Correspondence: olivier.fardel@univ-rennes1.fr; Tel.: +33-223-23-4880
}

Academic Editor: Yvonne Perrie

Received: 26 January 2016; Accepted: 6 April 2016; Published: 12 April 2016

\begin{abstract}
In vitro evaluation of P-glycoprotein (P-gp) inhibitory potential is now a regulatory issue during drug development, in order to predict clinical inhibition of P-gp and subsequent drug-drug interactions. Assays for this purpose, commonly based on P-gp-expressing cell lines and digoxin as a reference P-gp substrate probe, unfortunately exhibit high variability, raising thus the question of developing alternative or complementary tests for measuring inhibition of P-gp activity. In this context, the present study was designed to investigate the use of the fluorescent dye rhodamine 123 as a reference P-gp substrate probe for characterizing P-gp inhibitory potential of 16 structurally-unrelated drugs known to interact with P-gp. 14/16 of these P-gp inhibitors were found to increase rhodamine 123 accumulation in P-gp-overexpressing MCF7R cells, thus allowing the determination of their P-gp inhibitory potential, i.e., their half maximal inhibitor concentration $\left(\mathrm{IC}_{50}\right)$ value towards P-gp-mediated transport of the dye. These $\mathrm{IC}_{50}$ values were in the range of variability of previously reported $\mathrm{IC}_{50}$ for P-gp and can be used for the prediction of clinical P-gp inhibition according to Food and Drug Administration (FDA) criteria, with notable sensitivity (80\%). Therefore, the data demonstrated the feasibility of the use of rhodamine 123 for evaluating the P-gp inhibitory potential of drugs.
\end{abstract}

Keywords: P-glycoprotein; inhibition; drug-drug interactions; rhodamine 123; digoxin

\section{Introduction}

P-glycoprotein (P-gp), encoded by the multidrug resistance (MDR) 1 gene (also known as $A B C B 1)$, is an ATP-binding cassette $(\mathrm{ABC})$ membrane transporter acting as a drug efflux pump [1,2]. This membrane protein was initially characterized as overexpressed in tumoral cells exhibiting multiple resistance to a wide variety of structurally-unrelated anticancer drugs [3]. P-gp was next shown to be physiologically expressed in tissues and organs involved in pharmacokinetics, such as intestine, liver, kidney and blood-brain barrier, and to handle drugs belonging to various pharmacological classes. By this way, P-gp plays a notable role in intestinal absorption, brain distribution, and hepatobiliary and/or renal secretion of several marketed drugs, including the cardiotonic drug digoxin and the hypotensive agent talinolol; P-gp can therefore be considered as a key actor of the pharmacokinetics of these compounds [4].

P-gp activity can be inhibited by a wide range of drugs, which can lead to drug-drug interactions (DDIs) due to impairment of pharmacokinetics of a drug substrate for P-gp (the "victim") by the 
inhibitor drug (the "perpetrator"). This notably concerns digoxin, for which various clinical DDIs involving P-gp have been reported [5]. Indeed, digoxin has a narrow therapeutic index and even slight changes in plasma exposure due to alteration of P-gp activity can alter its efficacy and/or safety. Owing to this implication of P-gp in DDIs, the determination of P-gp inhibitory potential is now required by drug regulatory agencies such as the US Food and Drug Administration (FDA) and the European Medicines Agency (EMA) for new drugs developed by pharmaceutical companies [6]. In particular, the FDA recommends determining in vitro half maximal inhibitor concentration $\left(\mathrm{IC}_{50}\right)$ values towards P-gp and provides decision criteria using these $\mathrm{IC}_{50}$ values for evaluating the risk of a clinically significant DDI resulting from P-gp inhibition. A clinical study with digoxin as a P-gp substrate thus must be considered when the maximum total plasma (bound plus unbound) concentration of the investigated drug at steady state $\left(\left[\mathrm{I}_{1}\right]\right)$ divided by its in vitro P-gp inhibitory potency $\left(\mathrm{IC}_{50}\right)$ is greater than or equal to 0.1 or, for orally administered drugs, its nominal gut concentration $\left(\left[\mathrm{I}_{2}\right]\right)$ divided by its $\mathrm{IC}_{50}$ towards $\mathrm{P}$-gp is greater than or equal to 10 [7].

Assays for determining in vitro P-gp inhibitory potential $\left(\mathrm{IC}_{50}\right)$ are commonly based on P-gp-expressing cell lines, such as Caco-2 cell line and MDR1-transfected MDCKII or LLC-PK1 cell lines, and digoxin as a marketed reference, a non-metabolized and sensitive P-gp probe $[8,9]$, for which many clinical DDI data are available [5]. Inside-out P-gp vesicles and $N$-methylquininide or vinblastine as P-gp substrates are alternatively used [8]. Recent data from the "P-gp IC 50 working group" have, however, revealed a marked inter-laboratory variability in P-gp IC 50 determinations from digoxin transport assays across polarized cell monolayers or from P-gp vesicles assays [10], resulting in the questioning of the predictability of P-gp-mediated DDIs from in vitro data [11]. Moreover, the use of digoxin as a specific P-gp probe in transepithelial efflux assays has been recently challenged because digoxin is handled by (an) as yet unidentified basolateral uptake process(es) in intestinal cells [12]. It also required rather elaborated and specific bioanalytical methods and equipment, i.e., a scintillation counter when using radiolabeled digoxin or a liquid chromatography coupled to tandem mass spectrometry (LC-MS/MS) for quantifying unlabeled digoxin. These concerns about the digoxin assay raise the question of the development of alternative assays for P-gp IC $\mathrm{I}_{50}$ determination. In this context, fluorescent dye-based assays are likely to be considered, notably because they are relatively easy to use and are applicable to high throughput assays [13]. Among fluorescence dyes transported by P-gp, rhodamine 123 is likely a major one, which has been successfully applied to the detection of P-gp activity in a wide range of studies [13-16], with a rather high sensitivity when compared to the use of other dyes $[17,18]$. However, whether a rhodamine 123 assay may allow the evaluation of P-gp inhibitory potential in a convenient and calibrated manner remains to be established. The present study was therefore designed to determine $\mathrm{IC}_{50}$ values for 16 reference P-gp inhibitors using a rhodamine 123 accumulation assay and to investigate their potential usefulness for the prediction of P-gp-related clinical relevant DDIs, notably in comparison with $\mathrm{IC}_{50}$ data from digoxin transport assays available in the literature.

\section{Materials and Methods}

\subsection{Chemicals}

Rhodamine 123, amiodarone, carvedilol, cyclosporin A, diltiazem, elacridar, felodipine, fumitremorgin $C$, isradipine, itraconazole, mibefradil, nicardipine, nitrendipine, probenecid, quinidine, sertraline, troglitazone, verapamil, and zosuquidar were provided by Sigma-Aldrich (Saint-Quentin Fallavier, France).

\subsection{Cell Culture}

Parental human mammary MCF7 cells and P-gp-overexpressing MCF7R cells [19], generated by stepwise selection with doxorubicin [20], were cultured in Dulbecco's modified Eagle medium 
(DMEM) (Life Technologies, Saint-Aubin, France), supplemented with 10\% $(v / v)$ fetal calf serum, $100 \mathrm{IU} / \mathrm{mL}$ penicillin, and $100 \mu \mathrm{g} / \mathrm{mL}$ streptomycin.

\subsection{RNA Isolation and Analysis}

Total RNAs were extracted using the TRI reagent (Sigma-Aldrich). RNA was then subjected to a reverse transcription-quantitative polymerase chain reaction (RT-qPCR), using the RT kit from Applied Biosystems (Foster City, CA, USA), the fluorescent dye SYBR Green methodology, and an ABI Prism 7300 detector (Applied Biosystems), as described previously [21]. Gene-specific primers for drug transporters and 18S RNA were used exactly as already reported [22]. The specificity of each gene amplification was verified at the end of qPCR reactions through analysis of dissociation curves of the PCR products. Amplification curves were analyzed with ABI Prism 7000 SDS software, using the comparative cycle threshold method. Relative quantification of the steady-state target mRNA levels was calculated after normalization of the total amount of cDNA tested to the 18S RNA endogenous reference using the $2^{(-\Delta C t)}$ method. Data were finally expressed in arbitrary units relative to $18 \mathrm{~S} R N A$ content as described previously [23].

\subsection{Western Blot Analysis}

Cellular protein extracts were prepared as already described [24]. Protein lysates were then separated on polyacrylamide gel and electrophoretically transferred onto Protan ${ }^{\circledR}$ nitrocellulose membranes (Whatman GmbH, Dassel, Germany). After blocking with Tris-buffered saline containing $4 \%(v / v)$ bovine serum albumin for $30 \mathrm{~min}$ at room temperature, membranes were incubated overnight at $4{ }^{\circ} \mathrm{C}$ with primary antibodies against P-gp (clone C219) (Alexis Biochemicals, Lausen, Switzerland) or HSC70 (Santa Cruz Biotechnology, CA, USA), used here as a control for gel loading and transfer. After washing, membranes were next re-incubated with appropriate horseradish peroxidase-conjugated secondary antibodies (Dako, Glostrup, Denmark). Immunolabeled proteins were finally visualized by chemiluminescence.

\subsection{Rhodamine 123 Accumulation Assay}

P-gp activity was determined by measuring intracellular accumulation of rhodamine 123 in MCF7R cells in the absence or presence of P-gp inhibitors, as previously reported [25]. Briefly, for a typical $\mathrm{IC}_{50}$ determination experiment, cells were incubated at $37^{\circ} \mathrm{C}$ with $5.25 \mu \mathrm{M}$ rhodamine 123 for $30 \mathrm{~min}$, in the presence or absence of various concentrations of P-gp inhibitors. After washing in phosphate-buffered saline, cells were lysed in distilled water, and intracellular levels of rhodamine 123 were quantified by spectrofluorimetry using a SpectraMax Gemini SX spectrofluorimeter (Molecular Devices, Sunnyvale, CA, USA) (excitation and emission wavelengths were 485 and $535 \mathrm{~nm}$, respectively). Data were expressed as \% of rhodamine 123 accumulation in control cells not exposed to P-gp inhibitors, arbitrarily set at $100 \%$. IC $_{50}$ values for inhibition of P-gp activity, which correspond to half maximal effective concentration $\left(\mathrm{EC}_{50}\right)$ values for increasing rhodamine 123 accumulation, were next determined by 4 parameter logistic non-linear regressions using the Prism software (GraphPad software, La Jolla, CA, USA).

\subsection{Data Analysis}

Experimental data were routinely expressed as means \pm SEM from at least three independent experiments. Statistical analysis of quantitative data was performed with a Student's $t$-test, analysis of variance (ANOVA), followed by Dunnett's post-hoc test or non-parametric Spearman rank correlation using the Prism software. The criterion of significance was $p<0.05$.

Analysis of $\left[\mathrm{I}_{1}\right] / \mathrm{IC}_{50}$ and $\left[\mathrm{I}_{2}\right] / \mathrm{IC}_{50}$ ratio in relation to relevance or non relevance of clinical DDI studies dealing with P-gp and digoxin was performed using a binary classification decision tree, given a fixed discrimination threshold, resulting in four possible outcomes [26]: true positive (TP)—in vitro data is in agreement with a relevant clinical digoxin DDI; false negative (FN) — in vitro data is not in 
agreement with a relevant clinical digoxin DDI; false positive (FP) — in vitro data is not in agreement with a non relevant clinical digoxin DDI; and true negative (TN) - in vitro data is in agreement with a non relevant clinical digoxin DDI. The following performance metrics were next determined using the following equations:

$$
\begin{gathered}
\text { Accuracy }(\%)=(\text { Number of TP }+ \text { Number of TN }) \times 100 / \text { Total number of studies } \\
\text { Sensitivity }(\%)=\text { Number of TP } \times 100 /(\text { Number of TP }+ \text { Number of FN }) \\
\text { Specificity }(\%)=\text { Number of TN } \times 100 /(\text { Number of TN }+ \text { Number of FP })
\end{gathered}
$$

\section{Results and Discussion}

\subsection{Expression of MDR1/P-gp in MCF7 and MCF7R Cells}

We first characterized the expression of MDR1 mRNAs and P-gp in MCF7R cells, used as reference P-gp-overexpressing cells in our rhodamine accumulation assay. These cells were found to markedly overexpress MDR1 mRNAs (Figure 1a) and P-gp (Figure 1b) when compared to parental MCF7 cells. By contrast, MCF7R cells, as well as MCF7 cells, exhibited no detectable mRNA expression of other transporters that have been demonstrated to handle rhodamine 123 such as mutated breast cancer resistance protein (BCRP/ABCG2) [27], organic cation transporter (OCT) 1 (SLC22A1), OCT2 (SLC22A2) [28], and organic anion-transporting polypeptide (OATP) 1A2 (SLCO1A2) [29] (Figure 1a). With respect to mRNA expression of additional ABC efflux pumps, such as multidrug resistance-associated protein (MRP) 1 (ABCC1), MRP2 (ABCC2), and MRP3 (ABCC3), MCF7 and MCF7R cells exhibited similarly low expression of MRP1, whereas MRP2 and MRP3 were not expressed (MCF7R cells) or only poorly expressed (MCF7 cells) (Figure 1a). MCF7R cells thus clearly showed overexpression of P-gp when compared to MCF7 cells, without notable expression of other transporters, which fully justifies the use of these cells for specifically studying P-gp activity.

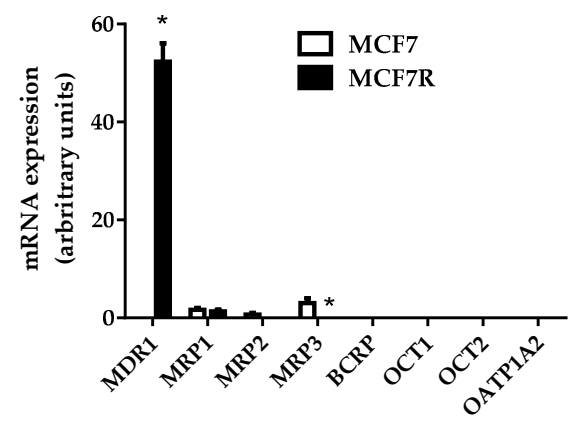

(a)

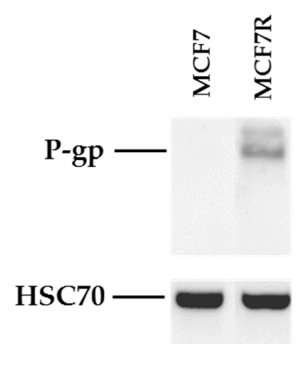

(b)

Figure 1. MDR1 mRNA and P-gp expression in MCF7 and MCF7R cells. (a) Drug transporter mRNA expression determined by RT-qPCR. Data are expressed as arbitrary units and are the means \pm SEM of three independent assays. ${ }^{*}, p<0.05$ when compared to transporter mRNA expression found in MCF7 cells. (b) P-gp expression analyzed via Western blot. Data shown are representative of three independent assays.

\subsection{Rhodamine 123 Accumulation in MCF7 and MCF7R Cells}

As shown in Figure 2a, MCF7R cells poorly accumulated rhodamine 123 when compared to parental MCF7 cells, thus reflecting P-gp-mediated efflux of the fluorescent dye in MCF7R cells. In the presence of the reference P-gp inhibitor verapamil, used at a $50-\mu \mathrm{M}$ concentration known to fully inhibit P-gp activity [30], rhodamine 123 accumulation in MCF7R cells was restored to the level found in MCF7 cells (Figure 2a); by contrast, verapamil did not alter rhodamine 123 level in MCF7 cells. In addition to verapamil, other reference P-gp inhibitors such as cyclosporin A [31], 
elacridar [32], and zosuquidar [33] increased dye accumulation in MCF7R cells (Figure 2b). By contrast, probenecid and fumitremorgin C, reference inhibitors for MRPs and BCRP, respectively [34,35], failed to augment rhodamine 123 levels in MCF7R cells (Figure 2b). Taken together, these data demonstrate that the use of the rhodamine 123 assay was adequate for specifically measuring P-gp activity and its inhibition by reference P-gp inhibitors in MCF7R cells. This conclusion is, moreover, reinforced by the fact that rhodamine 123 is not a substrate for cytochrome P-450 3A [36], in contrast to many other P-gp substrates [37], thus discarding the hypothesis that the modulation of cellular rhodamine 123 accumulation by some P-gp inhibitors may be due to interference with cytochrome P-450 3A activity. It should, however, be kept in mind when interpreting data from rhodamine 123 transport assay that the dye can be partly metabolized to rhodamine 110 through deacetylation followed by its glucuronidation [38]. Moreover, the fact that mitochondrial membrane potential is an additional factor contributing to rhodamine 123 accumulation [39] must also be formally taken into account. In this context, however, it is noteworthy that drugs interfering with mitochondria usually decrease, and not increase, mitochondrial transmembrane potential [40], thus allowing easy discrimination of drugs inhibiting P-gp (that increase cellular accumulation of rhodamine 123 in P-gp expressing cells through inhibiting its efflux) from drugs interacting with mitochondria (that reduce cellular accumulation of rhodamine 123 through lowering mitochondrial transmembrane potential).

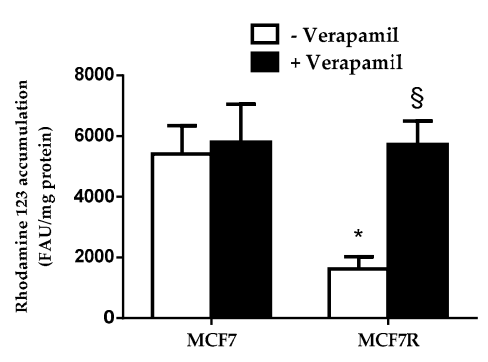

(a)

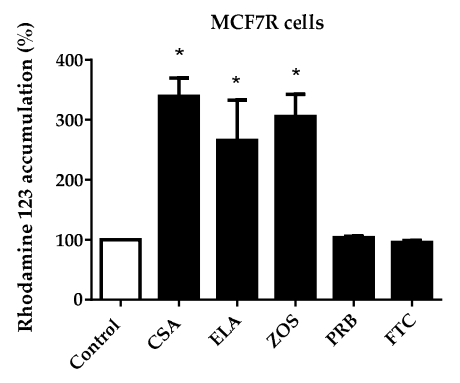

(b)

Figure 2. Accumulation of rhodamine 123 in MCF7 and MCF7R cells. (a) Cells were exposed to $5.25 \mu \mathrm{M}$ rhodamine 123 for $30 \mathrm{~min}$ at $37^{\circ} \mathrm{C}$ in the absence or presence of $50 \mu \mathrm{M}$ verapamil. After washing, rhodamine 123 accumulation was quantified by spectrofluorimetry. Data are expressed as fluorescence arbitrary unit (FAU) $/ \mathrm{mg}$ protein and are the means \pm SEM of three independent experiments. ${ }^{*}, p<0.05$ when compared to MCF7 cells; $\S, p<0.05$ when compared to counterparts not exposed to verapamil. (b) MCF7R cells were exposed to $5.25 \mu \mathrm{M}$ rhodamine 123 for $30 \mathrm{~min}$ at $37^{\circ} \mathrm{C}$ in the absence (control) or presence of $100 \mu \mathrm{M}$ cyclosporin A (CSA), $1 \mu \mathrm{M}$ elacridar (ELA), $1 \mu \mathrm{M}$ zosuquidar (ZOS), $2 \mathrm{mM}$ probenecid (PRB) or $10 \mu \mathrm{M}$ fumitremorgin C (FTC). After washing, cellular rhodamine 123 accumulation was quantified by spectrofluorimetry. Data are expressed as \% of fluorescent dye accumulation in control MCF7R cells exposed only to rhodamine 123, arbitrarily set at 100\%, and are the means \pm SEM of three independent assays. ${ }^{*}, p<0.05$ when compared to control cells.

\subsection{Determination of P-gp IC 50 Values for a Range of Structurally-Unrelated Reference P-gp Inhibitors}

Concentration-dependent effects of 16 structurally-unrelated reference P-gp inhibitors on cellular accumulation of rhodamine 123 were determined in MCF7R cells. These inhibitors, listed in Table 1, have been well characterized previously for their inhibitory potential towards P-gp-mediated transport of digoxin both in vitro [5,10,41] and in the clinic [41,42]. Among these 16 chemicals, 14 were found to inhibit P-gp-mediated efflux of rhodamine 123 in MCF7R cells, i.e., they increased cellular accumulation of rhodamine 123 (Table 1). These effects were concentration-dependent; examples of curves for increased rhodamine 123 accumulation versus inhibitor concentrations are shown in Figure 3 for verapamil and cyclosporin $\mathrm{A}$. IC $\mathrm{IC}_{50}$ values towards $\mathrm{P}$-gp activity were finally determined for each active $\mathrm{P}$-gp inhibitor by non-linear regression of rhodamine 123 assay data (Table 1 ). These $\mathrm{IC}_{50}$ values were found to range from $0.05 \mu \mathrm{M}$ (for elacridar) to $250.5 \mu \mathrm{M}$ (for nitrendipine). 
Two compounds, i.e., itraconazole and sertraline, were found not to increase rhodamine 123 accumulation in MCF7R cells when used up to $100 \mu \mathrm{M}$, thus suggesting that they do not inhibit P-gp-mediated efflux of rhodamine 123 (Table 1). These compounds have, however, been shown to inhibit P-gp-mediated efflux of digoxin in vitro [41]; moreover, itraconazole can block clinical P-gp activity in humans $[43,44]$, whereas, by contrast, inhibition of P-gp activity by sertraline observed in vitro is unlikely to be of major clinical significance [45]. Interestingly, itraconazole has been shown to block P-gp-mediated efflux of the anticancer drug daunorubicin or of acetoxymethyl ester of the dye calcein, but not that of rhodamine 123 in MDR1-transfected cells or in intestinal Caco-2 cells $[46,47]$. The reasons for such differences with respect to P-gp activity inhibition according to substrates are likely due to the presence of multiple drug binding sites on P-gp, with which P-gP substrates and inhibitors differently interact [47]. The best characterized sites most likely correspond to the H-site (binding Hoechst 33482), the R-site (binding rhodamine 123), and the P-site (binding prazosine and progesterone) $[48,49]$. In this context, itraconazole and sertraline may be presumed to not, or only poorly, interact with the R-site of P-gp, which suggests that the use of rhodamine 123 as a P-gp substrate fails to detect some P-gp inhibitors. Inhibition of P-gp by drugs is therefore likely substrate-dependent [50]. The use of different substrates interacting specifically with the different drug binding sites of P-gp should therefore be considered theoretically in order to accurately characterize the putative P-gp inhibitory potential of a given drug. This would require detailed knowledge of the specific P-gp substrate binding site involved in drug binding, which unfortunately is not available yet-not even for relevant P-gp substrates like digoxin. In addition, a fourth site on P-gp, which may bind non-transported modulators like elacridar or nicardipine [51], must also be considered. This site has been hypothesized to be a regulatory site, interacting with other sites in an allosteric manner [51], thus likely explaining why elacridar and nicardipine inhibit transport of rhodamine 123 (Table 1), presumably without binding to the R-site.

Table 1. P-gp inhibitory potential ( $\mathrm{IC}_{50}$ values) based on rhodamine 123 accumulation assay.

\begin{tabular}{ccccc}
\hline Drug & $\begin{array}{c}\mathbf{I C}_{\mathbf{5 0}}(\boldsymbol{\mu M}) \\
\text { (Rhodamine 123) }^{\mathbf{1}}\end{array}$ & $\begin{array}{c}\mathbf{I C}_{\mathbf{5 0}}(\boldsymbol{\mu M}) \\
\text { (Digoxin) }^{\mathbf{2}}\end{array}$ & $\begin{array}{c}\text { Ratio } \\
\mathbf{I C}_{\mathbf{5 0}} \begin{array}{c}\text { Rhodamine 123/ } \\
\text { IC }_{\mathbf{5 0}} \text { Digoxin }\end{array}\end{array}$ & $\begin{array}{c}\text { IC }_{\mathbf{5 0}} \text { Range for P-gp } \\
\text { Inhibition (-fold) }\end{array}$ \\
\hline Amiodarone & $22.9 \pm 2.0$ & 9.6 & 2.4 & 27 \\
Carvedilol & $3.4 \pm 1.2$ & 1.3 & 2.7 & 168 \\
Cyclosporin A & $4.8 \pm 1.1$ & 1.1 & 4.4 & NR $^{4}$ \\
Diltiazem & $11.7 \pm 2.2$ & 4.6 & 2.6 & 76 \\
Elacridar & $0.05 \pm 0.01$ & 0.03 & 1.9 & NR \\
Felodipine & $127.3 \pm 6.0$ & 4.2 & 30.3 & 188 \\
Isradipine & $83.1 \pm 10.8$ & 7.7 & 10.8 & 24 \\
Itraconazole & No inhibition & 1.8 & NA & NR \\
Mibefradil & $4.7 \pm 1.8$ & 1.9 & 2.5 & 48 \\
Nicardipine & $19.4 \pm 1.5$ & 3.8 & 5.1 & 78 \\
Nitrendipine & $250.5 \pm 43.8$ & 18.2 & 13.8 & 72 \\
Quinidine & $51.3 \pm 1.5$ & 4.9 & 10.5 & 98 \\
Sertraline & No inhibition & 12.9 & NA & 18 \\
Troglitazone & $44.1 \pm 7.7$ & 15.9 & 2.8 & 36 \\
Verapamil & $14.3 \pm 1.4$ & 2.8 & 5.1 & 796 \\
Zosuquidar & $0.18 \pm 0.12$ & 0.02 & 9.7 & NR \\
\hline
\end{tabular}

${ }^{1}$ expressed as mean \pm SEM of three independent assays; ${ }^{2}$ data from Poirier et al. [41]; ${ }^{3}$ corresponds to the ratio of the highest versus lowest $\mathrm{IC}_{50}$ values determined from five experimental measurements based on digoxin transport and vesicle uptake of P-gp substrates, according to Lee et al. [11]; ${ }^{4} \mathrm{NR}$, not reported; ${ }^{5}$ no inhibition at $100 \mu \mathrm{M} ;{ }^{6} \mathrm{NA}$, not applicable.

\subsection{Comparison of $I C_{50}$ Values for P-gp Inhibition Determined from Rhodamine 123 and Digoxin Transport Assays}

Next, $\mathrm{IC}_{50}$ values for $14 \mathrm{P}$-gp inhibitors measured by the rhodamine 123 assay (Table 1) were compared to $\mathrm{IC}_{50}$ values determined by the digoxin bidirectional transport assay in MDR1-transfected 
cells as reported by Poirier et al. [41]. IC $_{50}$ values for P-gp-mediated inhibition of rhodamine 123 transport were higher than those from digoxin transport assays. This may be due to the nature of the final parameter obtained for generating $\mathrm{IC}_{50}$ from digoxin assays, i.e., the digoxin efflux ratio (ER). Indeed, this parameter, corresponding to the ratio of digoxin apparent permeability in the basolateral-to-apical direction ( $\left.\mathrm{P}_{\mathrm{app}} \mathrm{BA}\right)$ versus that in the apical-to-basolateral direction $\left(\mathrm{P}_{\text {app }} \mathrm{AB}\right)$, has been shown to be particularly sensitive to P-gp inhibitors, much more than the parameters $P_{a p p} A B$ or $\mathrm{P}_{\mathrm{app}} \mathrm{BA}$. $\mathrm{IC}_{50}$ values based on digoxin $\mathrm{P}_{\mathrm{app}} \mathrm{AB}$ or $\mathrm{P}_{\mathrm{app}} \mathrm{BA}$ for a wide range of P-gp inhibitors were thus higher than those generated from digoxin ER [41], which may be due to the fact that the influence of passive permeability is maximally neglected with the ER parameter [52]. Interestingly, the ratio " $\mathrm{IC}_{50}$ rhodamine 123 assay" / " $\mathrm{IC}_{50}$ digoxin assay", which can be considered as the fold-variability, ranged from 1.9-fold (for elacridar) to 30.3-fold (for felodipine) (Table 1). They remained, thus, for each of the $14 \mathrm{P}$-gp inhibitors active on rhodamine 123 transport, in the $\mathrm{IC}_{50}$ range established from five experimental measurements based on digoxin transport and vesicle uptake of P-gp substrates [11] (Table 1). Such data, therefore, underline the potential relevance of the rhodamine 123 accumulation assay for evaluating the P-gp inhibitory potential. In this context, the rather extended $\mathrm{IC}_{50}$ range for P-gp inhibitors, reflecting the now well-established high level of variability for P-gp inhibitory potential characterization [11], deserves attention. The reasons for discrepancies between determinations for a specific P-gp inhibitor remain to be unequivocally specified; they could be linked to various causes, which, moreover, can add up. Differences in the cell type used for in vitro assays, which may differentially express additional non-P-gp transporters interacting with P-gp substrates such as digoxin [12,53] or may constitutively express non-human P-gp when they are of animal origin [54], may be suspected. The nature of the final measured parameter, i.e., for example, intracellular accumulation of rhodamine 123 in P-gp-overexpressing MCF7R cells (in the present study) versus ER of digoxin across monolayers of MDR1-transfected cells (in the study of Poirier et al. [41]), may also be incriminated. Additionally, $\mathrm{IC}_{50}$ calculation methods as well as inter-laboratory variability should be considered, as discussed recently [10]. Nevertheless, it is noteworthy that $\mathrm{IC}_{50}$ values from rhodamine 123 assay showed highly significant correlation with those from the digoxin assay [41] (Figure 4), indicating that the two methods similarly ranked the P-gp inhibitors according to their inhibitory potential.

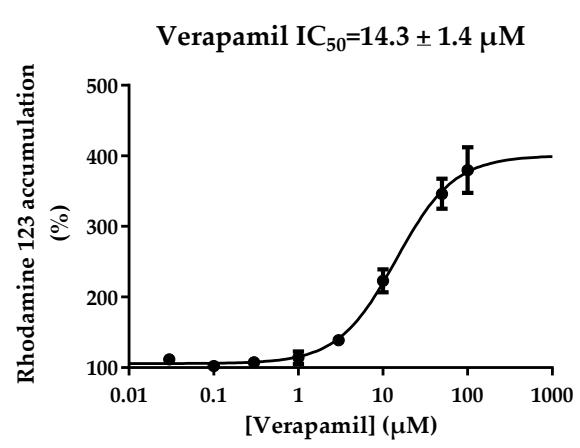

(a)

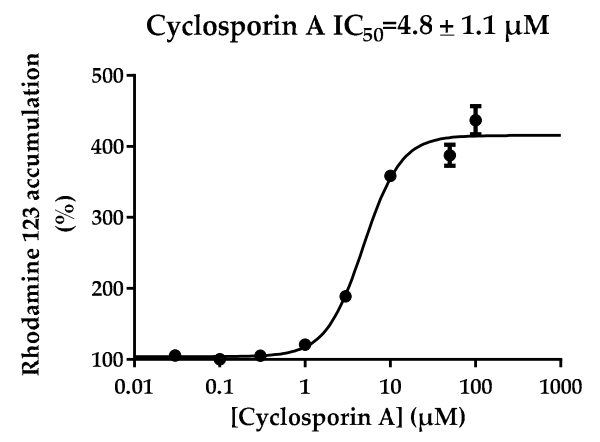

(b)

Figure 3. Concentration-dependent effects of verapamil and cyclosporin A on rhodamine 123 accumulation in MCF7R cells. Cells were exposed to $5.25 \mu \mathrm{M}$ rhodamine 123 for $30 \mathrm{~min}$ at $37^{\circ} \mathrm{C}$ in the absence or presence of various concentrations of (a) verapamil or (b) cyclosporin A. After washing, rhodamine 123 accumulation was quantified by spectrofluorimetry. Data are expressed as \% of rhodamine 123 levels found in control MCF7R cells not exposed to verapamil or cyclosporin A, arbitrarily set at $100 \%$ and are the means \pm SEM of three independent experiments. IC $_{50}$ values for P-gp activity, which correspond to $\mathrm{EC}_{50}$ values for increase of rhodamine 123 accumulation, are indicated at the top of the graphs. 
$\rho=0.86 ; p<0.0001$

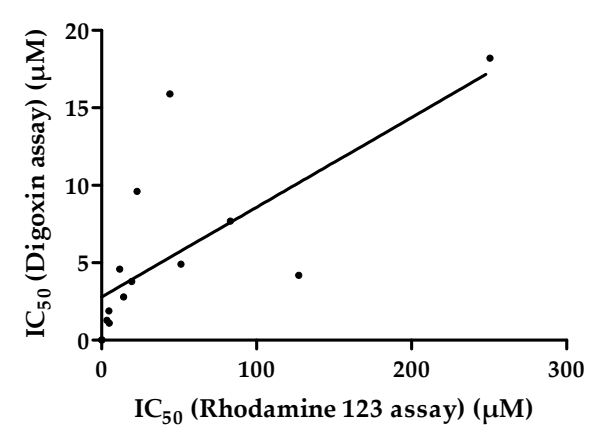

Figure 4. Correlation of $\mathrm{IC}_{50}$ values for P-gp inhibition from rhodamine 123 assay and digoxin assay. $\mathrm{IC}_{50}$ values towards P-gp activity for 14 drugs listed in Table 1, determined from rhodamine 123 accumulation assays and from digoxin bidirectional transport assays reported by Poirier et al. [41], were analyzed via the Spearman rank correlation method. Spearman coefficient $(\rho)$ and $p$ value are provided at the top of the correlation graph.

\subsection{Prediction of in Vivo P-gp Inhibition from Rhodamine 123 Accumulation Assays}

To analyze the putative relevance of $\mathrm{IC}_{50}$ values generated from rhodamine 123 accumulation for predicting clinical P-gp inhibition, we considered 26 clinical studies, involving digoxin as a victim drug and some of the $16 \mathrm{P}$-gp inhibitors investigated in the present study as perpetrator drugs. These studies were retrieved from 68 published studies listed by Poirier et al. [41]. Their clinical data, including plasma $\left[\mathrm{I}_{1}\right]$ or intestinal $\left[\mathrm{I}_{2}\right]$ concentrations of the perpetrator, have been detailed by Poirier et al. [41] and are summarized in Table 2. Twenty out of 26 studies described relevant DDI, i.e., the ratio area under the curve in the presence of the P-gp inhibitor (AUCi) versus that in the absence of the inhibitor (AUC) and/or the ratio peak plasma concentration in the presence of the P-gp inhibitor $\left(C_{\max } \mathrm{i}\right)$ versus that in absence of inhibitor $\left(C_{\max }\right)$ were $\geqslant 1.25$. These thresholds are thought to be significant regarding the toxicity of digoxin [5] and have consequently been retained in various previous studies $[5,41,42,52]$. The remaining 6/26 studies were classified as non relevant DDI (ratio AUCi/AUC $<1.25$ and ratio $\left.C_{\max } \mathrm{i} / C_{\max }<1.25\right)[41]$.

Further, the ratio $\left[\mathrm{I}_{1}\right] / \mathrm{IC}_{50}$ and $\left[\mathrm{I}_{2}\right] / \mathrm{IC}_{50}$ were calculated with $\mathrm{IC}_{50}$ values determined from the rhodamine 123 assay for each DDI study (data not shown) and were used to predict P-gp-related DDI for the 26 clinical studies according to FDA criteria $\left(\left[\mathrm{I}_{1}\right] / \mathrm{IC}_{50}>0.1\right.$ and $/$ or $\left.\left[\mathrm{I}_{2}\right] / \mathrm{IC}_{50}>10\right)$. Prediction results for the 26 clinical studies are indicated in Table 2. For the 20 clinically relevant DDI, 16 were found to be predicted correctly with $\mathrm{IC}_{50}$ values from rhodamine 123 assays and FDA criteria (Table 2), thus resulting in a rather high sensitivity (80.0\%) (Table 3). Omitting itraconazole, which does not interact with the R-site of P-gp as discussed above, the sensitivity even reaches $84.2 \%$, in the range of sensitivity values (around 80\%-90\%) previously reported for prediction of clinical P-gp inhibition [26,41,42]. By contrast, for the 6 studies with non-relevant DDI, only one was correctly predicted with $\mathrm{IC}_{50}$ values from the rhodamine 123 assay (Table 2), thus leading to a rather low specificity (16.7\%) and an intermediate rate of accuracy (65.4\%) (Table 3). Interestingly, using FDA criteria and $\mathrm{IC}_{50}$ values from digoxin ER assays [41] instead of those based on rhodamine 123 assays, similar predictions of clinical P-gp inhibition were obtained (Table 2), with, however, slightly higher sensitivity (95.0\%) and accuracy $(80.0 \%)$ and similarly low specificity (16.7\%) (Table 3 ). This low specificity for prediction of clinical P-gp inhibition, due to a high rate of false positives found with $\mathrm{IC}_{50}$ values from the rhodamine 123 or the digoxin assays, should be interpreted with caution, because of the small number of negative clinical DDI studies $(n=6)$ in the present study. However, it is noteworthy that a high rate of false positives (51\%) has also been reported in previous predictions of clinical P-gp inhibition with a much larger clinical data set $(n=101)$ [42]. This has been hypothesized 
to be related to the inappropriate nature of $\left[\mathrm{I}_{2}\right]$ criterion proposed by the FDA, for which a clinical digoxin study becomes warranted for many drugs with a quantifiable $\mathrm{IC}_{50}$ [11].

Table 2. Prediction of P-gp inhibition in 26 clinical DDI studies with digoxin as a victim drug, using FDA criteria and P-gp IC $_{50}$ values from rhodamine 123 accumulation or digoxin bidirectional transport [41] assays.

\begin{tabular}{|c|c|c|c|c|c|c|}
\hline \multirow[t]{2}{*}{ Perpetrator } & \multirow{2}{*}{$\begin{array}{l}{\left[\mathrm{I}_{1}\right] ;\left[\mathrm{I}_{2}\right]} \\
(\mu \mathrm{M}))^{1,2}\end{array}$} & \multirow{2}{*}{$\begin{array}{c}\text { AUCi/ } \\
\text { AUC }^{2,3}\end{array}$} & \multirow{2}{*}{$\begin{array}{c}C_{\max } \mathrm{i} / \\
\mathrm{C}_{\max }{ }^{2,4}\end{array}$} & \multirow{2}{*}{$\underset{\text { Relevance }^{5}}{\text { Clinical }}$} & \multicolumn{2}{|c|}{$\begin{array}{l}\text { P-gp Inhibition Prediction } \\
\text { (FDA Criteria }{ }^{6} \text { ) }\end{array}$} \\
\hline & & & & & Rhodamine $123 \mathrm{IC}_{50}$ & Digoxin $\mathrm{IC}_{50}{ }^{2}$ \\
\hline Carvelidol & $0.13 ; 62$ & 1.24 & 1.00 & - & $+(\mathrm{FP})^{7}$ & $+(\mathrm{FP})$ \\
\hline Diltiazem & $0.7 ; 868$ & 1.24 & 1.24 & - & $+(\mathrm{FP})$ & $+(\mathrm{FP})$ \\
\hline Mibefradil & $0.8 ; 404$ & 1.08 & 1.22 & - & $+(\mathrm{FP})$ & $+(\mathrm{FP})$ \\
\hline Nicardipine & $0.18 ; 250$ & 1.06 & 1.06 & - & $+(\mathrm{FP})$ & $+(\mathrm{FP})$ \\
\hline Nitrendipine & $0.015 ; 111$ & 1.09 & 1.22 & - & $-(\mathrm{TN})^{8}$ & $-(\mathrm{TN})$ \\
\hline Troglitazone & $3.62 ; 3,624$ & 1.04 & 1.05 & - & $+(\mathrm{FP})$ & $+(\mathrm{FP})$ \\
\hline Amiodarone & $2.49 ; 2479$ & 1.63 & 1.72 & + & $+(\mathrm{TP})^{9}$ & $+(\mathrm{TP})$ \\
\hline Amiodarone & $2.20 ; 4959$ & 1.68 & 1.84 & + & $+(\mathrm{TP})$ & $+(\mathrm{TP})$ \\
\hline Carvelidol & $0.52 ; 246$ & 1.2 & 1.60 & + & $+(\mathrm{TP})$ & $+(\mathrm{TP})$ \\
\hline Carvelidol & $0.13 ; 62$ & 1.56 & 1.38 & + & $+(\mathrm{TP})$ & $+(\mathrm{TP})$ \\
\hline Cyclosporin A & $2.8 ; 1167$ & NR 10 & 1.44 & + & $+(\mathrm{TP})$ & $+(\mathrm{TP})$ \\
\hline Diltiazem & $0.7 ; 579$ & 1.44 & 1.38 & + & $+(\mathrm{TP})$ & $+(\mathrm{TP})$ \\
\hline Diltiazem & $0.17 ; 579$ & 1.51 & 1.37 & + & $+(\mathrm{TP})$ & $+(\mathrm{TP})$ \\
\hline Felodipine & $0.03 ; 104$ & 1.18 & 1.34 & + & $-(\mathrm{FN})^{11}$ & $+(\mathrm{TP})$ \\
\hline Isradipine & $0.02 ; 54$ & 1.11 & 1.26 & + & $-(\mathrm{FN})$ & $-(\mathrm{FN})$ \\
\hline Itraconazole & $0.95 ; 1134$ & 1.68 & 1.34 & + & $-(\mathrm{FN})$ & $+(\mathrm{TP})$ \\
\hline Mibefradil & $2.42 ; 1211$ & 1.31 & 1.41 & + & $+(\mathrm{TP})$ & $+(\mathrm{TP})$ \\
\hline Mibefradil & $1.61 ; 807$ & 1.07 & 1.25 & + & $+(\mathrm{TP})$ & $+(\mathrm{TP})$ \\
\hline Nitrendipine & $0.03 ; 222$ & 1.15 & 1.57 & + & $-(\mathrm{FN})$ & $+(\mathrm{TP})$ \\
\hline Quinidine & $3.54 ; 3397$ & 1.76 & 1.75 & + & $+(\mathrm{TP})$ & $+(\mathrm{TP})$ \\
\hline Quinidine & $5.10 ; 2466$ & 2.65 & NR & + & $+(\mathrm{TP})$ & $+(\mathrm{TP})$ \\
\hline Quinidine & $4.5 ; 2466$ & NR & 1.44 & + & $+(\mathrm{TP})$ & $+(\mathrm{TP})$ \\
\hline Verapamil & $1.2 ; 704$ & 1.51 & 1.44 & + & $+(\mathrm{TP})$ & $+(\mathrm{TP})$ \\
\hline Verapamil & $0.026 ; 704$ & NR & 1.53 & + & $+(\mathrm{TP})$ & $+(\mathrm{TP})$ \\
\hline Verapamil & $0.058 ; 1056$ & NR & 1.61 & + & +(TP) & $+(\mathrm{TP})$ \\
\hline Verapamil & $0.033 ; 704$ & NR & 1.77 & + & $+(\mathrm{TP})$ & $+(\mathrm{TP})$ \\
\hline
\end{tabular}

${ }^{1}\left[\mathrm{I}_{1}\right]$ : total plasma concentration; [ $\left.\mathrm{I}_{2}\right]$ : gut concentration; ${ }^{2}$ data from Poirier et al. [41]; ${ }^{3}$ area under the curve in the presence (AUCi) or absence (AUC) of P-gp inhibitor. ${ }^{4}$ peak plasma concentration in the presence $\left(C_{\max }\right.$ ) or absence $\left(C_{\max }\right)$ of P-gp inhibitor. ${ }^{5}$ clinical relevance: $\mathrm{AUCi} / \mathrm{AUC} \geqslant 1.25$ and $/$ or $C_{\max } \mathrm{i} / C_{\max } \geqslant 1.25{ }^{6} \mathrm{FDA}$ criteria: $\left[\mathrm{I}_{1}\right] / \mathrm{IC}_{50}>0.1$ and $/$ or $\left[\mathrm{I}_{2}\right] / \mathrm{IC}_{50}>10 ;{ }^{7} \mathrm{FP}$ : false positive; ${ }^{8} \mathrm{TN}$ : true negative; ${ }^{9} \mathrm{TP}$ : true positive; ${ }^{10} \mathrm{NR}$ : not reported; ${ }^{11} \mathrm{FN}$ : false negative.

Table 3. Accuracy, sensitivity, and specificity of the prediction of clinical P-gp interactions with $\mathrm{IC}_{50}$ values generated from rhodamine 123 accumulation or digoxin bidirectional transport [41] assays, according to FDA criteria ${ }^{1}$.

\begin{tabular}{|c|c|c|}
\hline Performance Metrics & $\begin{array}{l}\text { Prediction from Rhodamine } \\
123 \text { Accumulation Assay }\end{array}$ & $\begin{array}{c}\text { Prediction from Digoxin } \\
\text { Transport Assay }\end{array}$ \\
\hline Accuracy $(\%)^{2}$ & 65.4 & 76.9 \\
\hline Sensitivity (\%) ${ }^{2}$ & 80.0 & 95.0 \\
\hline Specificity (\%) 2 & 16.7 & 16.7 \\
\hline
\end{tabular}

${ }^{1}$ FDA criteria: $\left[\mathrm{I}_{1}\right] / \mathrm{IC}_{50}>0.1$ and $/$ or $\left[\mathrm{I}_{2}\right] / \mathrm{IC}_{50}>10 ;{ }^{2}$ values were generated from the predictions of clinical P-gp interaction for the 26 clinical DDI studies summarized in Table 2 according to FDA criteria.

The high rate of false positives for prediction of clinical P-gp inhibition from in vitro data has led to the questioning of FDA thresholds [11] and to apply receiver operator characteristic analysis for establishing new criteria [41,42]. The "P-gp IC 50 working group", established with 23 participating pharmaceutical and contract research laboratories and one academic institution [10], has thus proposed to retain the ratio $\left[\mathrm{I}_{1}\right] / \mathrm{IC}_{50}>0.03$ and/or $\left[\mathrm{I}_{2}\right] / \mathrm{IC}_{50}>45$ [42] for predicting in vivo relevant P-gp interaction, whereas the threshold considered by Poirier et al. [41] refers only to intestinal concentration 
$\left(\left[\mathrm{I}_{2}\right] / \mathrm{IC}_{50}>6.5\right)$. Applying the "P-gp $\mathrm{IC}_{50}$ working group" criteria to $\mathrm{IC}_{50}$ values generated from rhodamine 123 accumulation assays allowed the enhancement of specificity and accuracy to $50 \%$ and $73.1 \%$ (Table 4 ), respectively, whereas sensitivity $(80 \%)$ remained constant when compared to the use of FDA criteria. By contrast, the application of the criteria proposed by Poirier et al. [41] failed to enhance specificity and accuracy (Table 4 ).

Table 4. Accuracy, sensitivity, and specificity of the prediction of clinical P-gp interactions with $\mathrm{IC}_{50}$ values generated from rhodamine 123 accumulation assays according to "P-gp $\mathrm{IC}_{50}$ working group" [42] or Poirier et al. [41] criteria.

\begin{tabular}{ccc}
\hline Performance Metrics & $\begin{array}{c}\text { Prediction with “P-gp IC } \\
\text { Working Group" Criteria }\end{array}$ & $\begin{array}{c}\text { Prediction with } \\
\text { Poirier } \text { et al. Criteria }\end{array}$ \\
\hline Accuracy (\%) ${ }^{1}$ & 73.1 & 65.4 \\
Sensitivity (\%) ${ }^{1}$ & 80.0 & 80.0 \\
Specificity (\%) $^{1}$ & 50.0 & 16.7
\end{tabular}

1 Values were generated from the predictions of clinical P-gp interaction for the 26 clinical DDI studies summarized in Table 2 according to "P-gp $\mathrm{IC}_{50}$ working group" criteria $\left(\left[\mathrm{I}_{1}\right] / \mathrm{IC}_{50}>0.03\right.$ and/or $\left.\left[\mathrm{I}_{2}\right] / \mathrm{IC}_{50}>45\right)[42]$ or to criteria by Poirier et al. $\left(\left[\mathrm{I}_{2}\right] / \mathrm{IC}_{50}>6.5\right)[41]$.

The rather notable sensitivity of the rhodamine 123 assay for predicting clinical P-gp interactions may be compatible with its use for in vitro screening of the P-gp inhibitory potential of drug candidates during their pharmaceutical development. However, limits of the rhodamine 123 assay already discussed above, notably its failure to detect P-gp inhibitors not interacting with the R-site of P-gp and the P-gp-unrelated factors that may affect cellular accumulation of the dye, must be kept in mind. In fact, an ideal experimental in vitro approach for predicting clinical P-gp inhibition may require the use of several P-gp assays in combination, with multiple P-gp substrates, as already suggested [47,50]. Rhodamine 123 assay may be one of these assays, especially convenient for drug screening and early development. Digoxin-based assay is also one major P-gp assays that must be considered in this context. Indeed, extensive data on clinical interactions of P-gp with digoxin are available in humans [5], allowing the close linking of in vitro behavior to in vivo pharmacokinetics behavior. Moreover, digoxin is recommended by the FDA as a reference P-gp substrate for in vivo clinical drug interaction studies [7].

\section{Conclusions}

The fluorescent dye rhodamine 123 was demonstrated to be convenient for characterizing the P-gp inhibitory potential of various reference P-gp inhibitors. As an exception, itraconazole and sertraline produce a negative result in the rhodamine 123 assay and are assumed not to interact with the R-site of P-gp. For drugs inhibiting efflux of rhodamine $123, \mathrm{IC}_{50}$ values towards transport of the dye, although higher than some available $\mathrm{IC}_{50}$ towards $\mathrm{P}$-gp-mediated digoxin efflux of $\mathrm{P}$-gp, were in the range of variability of previous reported $\mathrm{IC}_{50}$ for P-gp. Moreover, they can be used for the prediction of clinical P-gp inhibition according to FDA criteria, with a rather notable sensitivity $(80 \%)$. The findings indicate the suitability of the rhodamine 123-based assay for in vitro prediction of the clinical risk of interactions with P-gp, notably during drug screening and early development. However, the P-gp inhibitory potential of drugs not interacting with the R-site of P-gp is likely to be complementarily investigated using additional substrates of the pump, thus confirming that accurate prediction of clinically significant P-gp drug interactions require the use of multiple P-gp substrates [50].

Author Contributions: Elodie Jouan, Marc Le Vee, and Abdullah Mayati performed the experiments. Claire Denizot, Yannick Parmentier, and Olivier Fardel conceived and designed the experiments and interpreted data. Olivier Fardel wrote the paper.

Conflicts of Interest: The authors declare no conflict of interest. 


\section{References}

1. Gottesman, M.M.; Pastan, I. Biochemistry of multidrug resistance mediated by the multidrug transporter. Annu. Rev. Biochem. 1993, 62, 385-427. [CrossRef] [PubMed]

2. Fardel, O.; Lecureur, V.; Guillouzo, A. The P-glycoprotein multidrug transporter. Gen. Pharmacol. 1996, 27, 1283-1291. [CrossRef]

3. Bradley, G.; Juranka, P.F.; Ling, V. Mechanism of multidrug resistance. Biochim. Biophys. Acta 1988, 948, 87-128. [CrossRef]

4. Zhou, S.F. Structure, function and regulation of P-glycoprotein and its clinical relevance in drug disposition. Xenobiotica 2008, 38, 802-832. [CrossRef] [PubMed]

5. Fenner, K.S.; Troutman, M.D.; Kempshall, S.; Cook, J.A.; Ware, J.A.; Smith, D.A.; Lee, C.A. Drug-drug interactions mediated through P-glycoprotein: Clinical relevance and in vitro-in vivo correlation using digoxin as a probe drug. Clin. Pharmacol. Ther. 2009, 85, 173-181. [CrossRef] [PubMed]

6. Zhang, L.; Zhang, Y.D.; Strong, J.M.; Reynolds, K.S.; Huang, S.M. A regulatory viewpoint on transporter-based drug interactions. Xenobiotica 2008, 38, 709-724. [CrossRef] [PubMed]

7. Giacomini, K.M.; Huang, S.M.; Tweedie, D.J.; Benet, L.Z.; Brouwer, K.L.; Chu, X.; Dahlin, A.; Evers, R.; Fischer, V.; Hillgren, K.M.; et al. Membrane transporters in drug development. Nat. Rev. Drug Discov. 2010, 9, 215-236. [CrossRef] [PubMed]

8. $\quad$ Brouwer, K.L.; Keppler, D.; Hoffmaster, K.A.; Bow, D.A.; Cheng, Y.; Lai, Y.; Palm, J.E.; Stieger, B.; Evers, R. In vitro methods to support transporter evaluation in drug discovery and development. Clin. Pharmacol. Ther. 2013, 94, 95-112. [CrossRef] [PubMed]

9. Rautio, J.; Humphreys, J.E.; Webster, L.O.; Balakrishnan, A.; Keogh, J.P.; Kunta, J.R.; Serabjit-Singh, C.J.; Polli, J.W. In vitro P-glycoprotein inhibition assays for assessment of clinical drug interaction potential of new drug candidates: A recommendation for probe substrates. Drug Metab. Dispos. 2006, 34, 786-792. [CrossRef] [PubMed]

10. Bentz, J.; O'Connor, M.P.; Bednarczyk, D.; Coleman, J.; Lee, C.; Palm, J.; Pak, Y.A.; Perloff, E.S.; Reyner, E.; Balimane, P.; et al. Variability in P-glycoprotein inhibitory potency $\left(\mathrm{IC}_{50}\right)$ using various in vitro experimental systems: Implications for universal digoxin drug-drug interaction risk assessment decision criteria. Drug Metab. Dispos. 2013, 41, 1347-1366. [CrossRef] [PubMed]

11. Lee, C.A.; Kalvass, J.C.; Galetin, A.; Zamek-Gliszczynski, M.J. ITC commentary on the prediction of digoxin clinical drug-drug interactions from in vitro transporter assays. Clin. Pharmacol. Ther. 2014, 96, $298-301$. [CrossRef] [PubMed]

12. Lumen, A.A.; Li, L.; Li, J.; Ahmed, Z.; Meng, Z.; Owen, A.; Ellens, H.; Hidalgo, I.J.; Bentz, J. Transport inhibition of digoxin using several common P-gp expressing cell lines is not necessarily reporting only on inhibitor binding to P-gp. PLoS ONE 2013, 8, e69394. [CrossRef] [PubMed]

13. Fardel, O.; Le Vee, M.; Jouan, E.; Denizot, C.; Parmentier, Y. Nature and uses of fluorescent dyes for drug transporter studies. Expert Opin. Drug Metab. Toxicol. 2015, 11, 1233-1251. [CrossRef] [PubMed]

14. Fortuna, A.; Alves, G.; Falcao, A. In vitro and in vivo relevance of the P-glycoprotein probe substrates in drug discovery and development: Focus on rhodamine 123, digoxin and talinolol. J. Bioequiv. Availab. 2011, S2. [CrossRef]

15. Gattringer, C.L.; Drach, J.; Hofmann, J.; Grunicke, H. Rapid functional assay for the detection of multidrug-resistant cells using the fluorescent dye rhodamine 123. Blood 1991, 78, 1385-1387.

16. Drenou, B.; Fardel, O.; Amiot, L.; Fauchet, R. Detection of P-glycoprotein activity on normal and leukemic CD34+ cells. Leuk. Res. 1993, 17, 1031-1035. [CrossRef]

17. Lizard, G.; Roignot, P.; Maynadie, M.; Lizard-Nacol, S.; Poupon, M.F.; Bordes, M. Flow cytometry evaluation of the multidrug-resistant phenotype with functional tests involving uptake of daunorubicin, Hoechst 33342, or rhodamine 123: A comparative study. Cancer Detect. Prev. 1995, 19, 527-534. [PubMed]

18. Sarver, J.G.; Klis, W.A.; Byers, J.P.; Erhardt, P.W. Microplate screening of the differential effects of test agents on Hoechst 33342, rhodamine 123, and rhodamine 6G accumulation in breast cancer cells that overexpress P-glycoprotein. J. Biomol. Screen. 2002, 7, 29-34. [PubMed]

19. Morjani, H.; Aouali, N.; Belhoussine, R.; Veldman, R.J.; Levade, T.; Manfait, M. Elevation of glucosylceramide in multidrug-resistant cancer cells and accumulation in cytoplasmic droplets. Int. J. Cancer 2001, 94, 157-165. [CrossRef] [PubMed] 
20. Batist, G.; Tulpule, A.; Sinha, B.K.; Katki, A.G.; Myers, C.E.; Cowan, K.H. Overexpression of a novel anionic glutathione transferase in multidrug-resistant human breast cancer cells. J. Biol. Chem. 1986, 261, 15544-15549. [PubMed]

21. Le Vee, M.; Lecureur, V.; Stieger, B.; Fardel, O. Regulation of drug transporter expression in human hepatocytes exposed to the proinflammatory cytokines tumor necrosis factor-alpha or interleukin-6. Drug Metab. Dispos. 2009, 37, 685-693. [CrossRef] [PubMed]

22. Moreau, A.; Le Vee, M.; Jouan, E.; Parmentier, Y.; Fardel, O. Drug transporter expression in human macrophages. Fundam. Clin. Pharmacol. 2011, 25, 743-752. [CrossRef] [PubMed]

23. Le Vee, M.; Jouan, E.; Noel, G.; Stieger, B.; Fardel, O. Polarized location of SLC and ABC drug transporters in monolayer-cultured human hepatocytes. Toxicol. In Vitro 2015, 29, 938-946. [CrossRef] [PubMed]

24. van Grevenynghe, J.; Sparfel, L.; Le Vee, M.; Gilot, D.; Drenou, B.; Fauchet, R.; Fardel, O. Cytochrome P450-dependent toxicity of environmental polycyclic aromatic hydrocarbons towards human macrophages. Biochem. Biophys. Res. Commun. 2004, 317, 708-716. [CrossRef] [PubMed]

25. Le Vee, M.; Jouan, E.; Stieger, B.; Lecureur, V.; Fardel, O. Regulation of human hepatic drug transporter activity and expression by diesel exhaust particle extract. PLoS ONE 2015, 10, e0121232.

26. Cook, J.A.; Feng, B.; Fenner, K.S.; Kempshall, S.; Liu, R.; Rotter, C.; Smith, D.A.; Troutman, M.D.; Ullah, M.; Lee, C.A. Refining the in vitro and in vivo critical parameters for P-glycoprotein, $[\mathrm{I}] / \mathrm{IC}_{50}$ and $\left[\mathrm{I}_{2}\right] / \mathrm{IC}_{50}$, that allow for the exclusion of drug candidates from clinical digoxin interaction studies. Mol. Pharm. 2010, 7, 398-411. [CrossRef] [PubMed]

27. Honjo, Y.; Hrycyna, C.A.; Yan, Q.W.; Medina-Perez, W.Y.; Robey, R.W.; van de Laar, A.; Litman, T.; Dean, M.; Bates, S.E. Acquired mutations in the MXR/BCRP/ABCP gene alter substrate specificity in MXR/BCRP/ABCP-overexpressing cells. Cancer Res. 2001, 61, 6635-6639. [PubMed]

28. Jouan, E.; Le Vee, M.; Denizot, C.; Da Violante, G.; Fardel, O. The mitochondrial fluorescent dye rhodamine 123 is a high-affinity substrate for organic cation transporters (OCTs) 1 and 2. Fundam. Clin. Pharmacol. 2014, 28, 65-77. [CrossRef] [PubMed]

29. Forster, S.; Thumser, A.E.; Hood, S.R.; Plant, N. Characterization of rhodamine- 123 as a tracer dye for use in in vitro drug transport assays. PLoS ONE 2012, 7, e33253. [CrossRef] [PubMed]

30. Durie, B.G.; Dalton, W.S. Reversal of drug-resistance in multiple myeloma with verapamil. Br. J. Haematol. 1988, 68, 203-206. [CrossRef] [PubMed]

31. Twentyman, P.R. Cyclosporins as drug resistance modifiers. Biochem. Pharmacol. 1992, 43, 109-117. [CrossRef]

32. Hyafil, F.; Vergely, C.; Du Vignaud, P.; Grand-Perret, T. In vitro and in vivo reversal of multidrug resistance by GF120918, an acridonecarboxamide derivative. Cancer Res. 1993, 53, 4595-4602. [PubMed]

33. Dantzig, A.H.; Shepard, R.L.; Cao, J.; Law, K.L.; Ehlhardt, W.J.; Baughman, T.M.; Bumol, T.F.; Starling, J.J. Reversal of P-glycoprotein-mediated multidrug resistance by a potent cyclopropyldibenzosuberane modulator, LY335979. Cancer Res. 1996, 56, 4171-4179. [PubMed]

34. Versantvoort, C.H.; Bagrij, T.; Wright, K.A.; Twentyman, P.R. On the relationship between the probenecid-sensitive transport of daunorubicin or calcein and the glutathione status of cells overexpressing the multidrug resistance-associated protein (MRP). Int. J. Cancer 1995, 63, 855-862. [CrossRef] [PubMed]

35. Rabindran, S.K.; Ross, D.D.; Doyle, L.A.; Yang, W.; Greenberger, L.M. Fumitremorgin C reverses multidrug resistance in cells transfected with the breast cancer resistance protein. Cancer Res. 2000, 60, 47-50. [PubMed]

36. Yumoto, R.; Murakami, T.; Sanemasa, M.; Nasu, R.; Nagai, J.; Takano, M. Pharmacokinetic interaction of cytochrome P450 3A-related compounds with rhodamine 123, a P-glycoprotein substrate, in rats pretreated with dexamethasone. Drug Metab. Dispos. 2001, 29, 145-151. [PubMed]

37. Wacher, V.J.; Wu, C.Y.; Benet, L.Z. Overlapping substrate specificities and tissue distribution of cytochrome P450 3A and P-glycoprotein: Implications for drug delivery and activity in cancer chemotherapy. Mol. Carcinog. 1995, 13, 129-134. [CrossRef] [PubMed]

38. Sweatman, T.W.; Seshadri, R.; Israel, M. Metabolism and elimination of rhodamine 123 in the rat. Cancer Chemother. Pharmacol. 1990, 27, 205-210. [CrossRef] [PubMed]

39. Kim, M.; Cooper, D.D.; Hayes, S.F.; Spangrude, G.J. Rhodamine-123 staining in hematopoietic stem cells of young mice indicates mitochondrial activation rather than dye efflux. Blood 1998, 91, 4106-4117. [PubMed]

40. Varga, Z.V.; Ferdinandy, P.; Liaudet, L.; Pacher, P. Drug-induced mitochondrial dysfunction and cardiotoxicity. Am. J. Physiol. Heart Circ. Physiol. 2015, 309, H1453-H1467. [CrossRef] [PubMed] 
41. Poirier, A.; Cascais, A.C.; Bader, U.; Portmann, R.; Brun, M.E.; Walter, I.; Hillebrecht, A.; Ullah, M.; Funk, C. Calibration of in vitro multidrug resistance protein 1 substrate and inhibition assays as a basis to support the prediction of clinically relevant interactions in vivo. Drug Metab. Dispos. 2014, 42, 1411-1422. [CrossRef] [PubMed]

42. Ellens, H.; Deng, S.; Coleman, J.; Bentz, J.; Taub, M.E.; Ragueneau-Majlessi, I.; Chung, S.P.; Heredi-Szabo, K.; Neuhoff, S.; Palm, J.; et al. Application of receiver operating characteristic analysis to refine the prediction of potential digoxin drug interactions. Drug Metab. Dispos. 2013, 41, 1367-1374. [CrossRef] [PubMed]

43. Shimizu, M.; Uno, T.; Sugawara, K.; Tateishi, T. Effects of single and multiple doses of itraconazole on the pharmacokinetics of fexofenadine, a substrate of P-glycoprotein. Br. J. Clin. Pharmacol. 2006, 62, 372-376. [CrossRef] [PubMed]

44. Jalava, K.M.; Partanen, J.; Neuvonen, P.J. Itraconazole decreases renal clearance of digoxin. Ther. Drug Monit. 1997, 19, 609-613. [CrossRef] [PubMed]

45. Juurlink, D.N.; Mamdani, M.M.; Kopp, A.; Herrmann, N.; Laupacis, A. A population-based assessment of the potential interaction between serotonin-specific reuptake inhibitors and digoxin. Br. J. Clin. Pharmacol. 2005, 59, 102-107. [CrossRef] [PubMed]

46. Wang, E.J.; Lew, K.; Casciano, C.N.; Clement, R.P.; Johnson, W.W. Interaction of common azole antifungals with P-glycoprotein. Antimicrob. Agents Chemother. 2002, 46, 160-165. [CrossRef] [PubMed]

47. Schwab, D.; Fischer, H.; Tabatabaei, A.; Poli, S.; Huwyler, J. Comparison of in vitro P-glycoprotein screening assays: Recommendations for their use in drug discovery. J. Med. Chem. 2003, 46, 1716-1725. [CrossRef] [PubMed]

48. Shapiro, A.B.; Ling, V. Positively cooperative sites for drug transport by P-glycoprotein with distinct drug specificities. Eur. J. Biochem. 1997, 250, 130-137. [CrossRef] [PubMed]

49. Shapiro, A.B.; Fox, K.; Lam, P.; Ling, V. Stimulation of P-glycoprotein-mediated drug transport by prazosin and progesterone. Evidence for a third drug-binding site. Eur. J. Biochem. 1999, 259, 841-850. [CrossRef] [PubMed]

50. Zolnerciks, J.K.; Booth-Genthe, C.L.; Gupta, A.; Harris, J.; Unadkat, J.D. Substrate- and species-dependent inhibition of P-glycoprotein-mediated transport: Implications for predicting in vivo drug interactions. J. Pharm. Sci. 2011, 100, 3055-3061. [CrossRef] [PubMed]

51. Martin, C.; Berridge, G.; Higgins, C.F.; Mistry, P.; Charlton, P.; Callaghan, R. Communication between multiple drug binding sites on P-glycoprotein. Mol. Pharmacol. 2000, 58, 624-632. [PubMed]

52. Sugimoto, H.; Matsumoto, S.; Tachibana, M.; Niwa, S.; Hirabayashi, H.; Amano, N.; Moriwaki, T. Establishment of in vitro P-glycoprotein inhibition assay and its exclusion criteria to assess the risk of drug-drug interaction at the drug discovery stage. J. Pharm. Sci. 2011, 100, 4013-4023. [CrossRef] [PubMed]

53. Taub, M.E.; Mease, K.; Sane, R.S.; Watson, C.A.; Chen, L.; Ellens, H.; Hirakawa, B.; Reyner, E.L.; Jani, M.; Lee, C.A. Digoxin is not a substrate for organic anion-transporting polypeptide transporters oatp1a2, oatp1b1, oatp1b3, and oatp2b1 but is a substrate for a sodium-dependent transporter expressed in HEK293 cells. Drug Metab. Dispos. 2011, 39, 2093-2102. [CrossRef] [PubMed]

54. Li, J.; Wang, Y.; Hidalgo, I.J. Kinetic analysis of human and canine P-glycoprotein-mediated drug transport in MDR1-MDCK cell model: Approaches to reduce false-negative substrate classification. J. Pharm. Sci. 2013, 102, 3436-3446. [CrossRef] [PubMed]

(c) 2016 by the authors; licensee MDPI, Basel, Switzerland. This article is an open access article distributed under the terms and conditions of the Creative Commons Attribution (CC-BY) license (http://creativecommons.org/licenses/by/4.0/). 